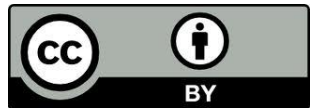

\title{
LOS FUNDAMENTOS ARQUETÍPICOS DE LA INTERRELACIÓN ENTRE RELIGIÓN, MITO, PSIQUE y SOCIEDAD
}

\author{
The archetypical fundamentals of the interrelation between \\ religion, myth, psyche and society
}

Daniel A. Wilhelm Licenciado en Psicología Doctor en Psicología Social Profesor Universitario (UMSA/UFLO) info@centrojung.com.ar

RESUMEN: En el presente trabajo se lleva a cabo un análisis de las interrelaciones entre religión, mito, psique y sociedad. La existencia de una base común, de naturaleza arquetípica, se pone en evidencia a través de la perspectiva de la psicología analítica de Carl G. Jung. Los conceptos de arquetipo e inconsciente colectivo, permiten trazar y esclarecer las vinculaciones existentes entre la conceptualización de las representaciones colectivas de Emile Durkheim, la noción de participación mística de Lucien Lévy-Bruhl, y el campo fenomenológico psicosocial de la dimensión arquetípica humana. De este modo, las formas, estructuras y funciones psicosociales de la religión, el mito, la psique y la sociedad, se presentan como los elementos constitutivos emergentes de un único y mismo proceso psico-socio-evolutivo.

Palabras clave: Religión; Mitos; Arquetipos; Psique, Sociedad

ABSTRACT: In the present work, an analysis of the interrelationships between religion, myth, psyche and society, is carried out. The existence of a common base, of archetypal nature, is put in evidence by means of the perspective of the analytical psychology of Carl G. Jung. The concepts of archetype and collective unconscious, allow to determinate and to clarify the existing linkages between the conceptualization of Emile Durkheim's collective representations, the notion of Lucien Lévy-Bruhl's mystical participation, and the phenomenological psychosocial field of the archetypal human dimension. Thus, the forms, structures and psychosocial functions of religion, myth, psyche and society, appear as the emergent constitutive elements of a unique and same psycho-socio-evolutive process.

Keywords: Religion; Myths; Archetypes; Psyche, Society 


\section{Introducción}

Las conceptualizaciones presentes en la psicología analítica de Carl G. Jung, han permitido trazar un conjunto de relaciones entre los distintos campos del conocimiento. Su perspectiva integradora de la evolución y la estructura del psiquismo humano, hicieron posible esclarecer diferentes puntos de contacto entre la psicología, la antropología, la sociología, las religiones comparadas, la mitología y otras ciencias humanas, en general.

En particular, la introducción de los conceptos junguianos de arquetipo e inconsciente colectivo, posibilitan la revisión y ampliación de las principales teorías antropológicas y sociológicas, desde las cuales se han intentado explicar muchos de los aspectos concernientes a la historia evolutiva de la humanidad, y de su realidad actual.

Por otro lado, la existencia de un sustrato común, de naturaleza arquetípica, permite explicar las vinculaciones entre las representaciones colectivas, los arquetipos, el inconsciente colectivo, el fenómeno de la participación mística, y el amplio campo fenomenológico psicosocial.

Así, se hace posible la construcción de una plataforma conceptual que facilita la descripción, explicación y comprensión de los aspectos más relevantes del mundo psíquico y social; tanto desde su perspectiva histórica, como de la actual. De esta manera, a lo largo del presente trabajo, se lleva a cabo un análisis de las interrelaciones entre la religión, el mito, la psique y la sociedad; como así también de sus formas, estructuras y funciones, las que participan y se integran, en última instancia, en un mismo proceso evolutivo que es determinante del desarrollo psíquico y social humano.

\section{La participación mística como base de la evolución conjunta entre la psique y el mundo}

Individuo y sociedad, o, formulado en un contexto psicológico, psique y mundo, no son entidades autónomas y separadas, sino que existe entre ambos una línea de continuidad; la que da lugar a una serie de interrelaciones e interdeterminaciones, por medio de las cuales ambos espacios se reconstruyen incesantemente a través de una sucesión de imágenes, interiorizadas y proyectadas, una y otra vez, en el continuum de la dimensión psico-social. Así, los límites entre la psique y el mundo resultan 
permeables al tránsito de imágenes y contenidos, de manera que la autorreferencialidad y la heterorreferencialidad conllevan, de un modo estructuralmente intrínseco, una dimensión especular en la que el "adentro" y el "afuera" no son más que convencionalismos, que permiten a los mecanismos psicológicos de control del Yo trazar una representación imaginaria del mundo, de matiz racional, en la que aún se supone posible una decodificación y estructuración lógica-causal de la "realidad".

El origen de la interacción dialéctica de este dinamismo evolutivo debe situarse en los comienzos mismos de la humanidad, formando parte de uno de los primeros mecanismos psicológicos de identificación del hombre con la naturaleza, al que Lucien Lévy-Bruhl denominó ley de participación o participación mística. (LÉVY-BRUHL, 1947, p. 84).

Entre las consecuencias fenomenológicas psíquicas inmediatas derivadas de la ley de participación se debe mencionar, principalmente, la suspensión o modificación en diferentes grados- de los principios lógicos de la razón, junto con sus categorías tradicionales de tiempo y espacio. De este modo, bajo la influencia mental de la participación mística, un sujeto, objeto o situación, pueden simultáneamente ser y no ser, estar y no estar, etcétera. Las condiciones de la percepción se modifican de manera sustancial; tiempo y espacio se distorsionan, la ontología del mundo y del propio ser se vuelven difusas, entrelazándose en una multiplicidad de posibles formas.

En consecuencia, según Lévy-Bruhl (1947), “los primitivos ven con los mismos ojos que nosotros: pero no perciben con el mismo espíritu. Podría decirse que sus percepciones están constituidas por un núcleo rodeado de una capa más o menos gruesa de representaciones de origen social" (LÉVY-BRUHL, 1947, p. 39). Y estas "representaciones de origen social", a las que Lévy-Bruhl hace referencia, son las representaciones colectivas, formuladas por Emile Durkheim (DURKHEIM, 2004) por primera vez en el año 1893. En función de ello, Lévy-Bruhl agrega que "el mundo exterior que perciben, difiere también del que nosotros percibimos. [...]. Pero es necesario tener en cuenta lo que incluyen las representaciones colectivas en cada una de sus percepciones." (LÉVY-BRUHL, 1947, p. 38). 


\section{La importancia de las representaciones colectivas en la obra de Emile Durkheim}

Tal como se ha mencionado, Emile Durkheim introduce el concepto de "representación colectiva" en el año 1893, en su obra "La división del trabajo social" (DURKHEIM, 2004). Sin embargo, es en su trabajo titulado "Las representaciones individuales y las representaciones colectivas" (DURKHEIM, 1951), del año 1898, donde realiza por primera vez un análisis detallado y una diferenciación de dichas representaciones. Con posterioridad, en el año 1912, el análisis y estudio de las representaciones colectivas es ampliado en su obra "Las formas elementales de la vida religiosa" (DURKHEIM, 1992). También, en su investigación acerca de la división del trabajo social, Durkheim introduce por primera vez, junto a la idea de representación colectiva, el concepto de conciencia colectiva. En relación a ella, postula que "el conjunto de las creencias y de los sentimientos comunes al término medio de los miembros de una misma sociedad, constituye un sistema determinado que tiene su vida propia, se le puede llamar la conciencia colectiva o común." (DURKHEIM, 2004, p. 82).

La introducción de este concepto representa un momento fundamental en la sociología de Durkheim, marcando un verdadero punto de inicio para el desarrollo de sus investigaciones posteriores, vinculadas con las representaciones colectivas. Encontramos de esta manera, entre las ideas principales de Durkheim, el hecho de que la conciencia colectiva o común se encuentra constituida, principalmente, por representaciones colectivas; lo que conlleva a la consecuencia de que, tal como lo formula Durkheim, "la vida social estaba hecha, toda ella, de representaciones" (DURKHEIM, 2003, p. 15).

Es importante destacar aquí, el carácter "supraindividual" de las representaciones colectivas, en contraposición al carácter individual de las representaciones subjetivas particulares, poniendo en evidencia su carácter y significado

\footnotetext{
${ }^{1}$ El concepto de "representación colectiva" de Durkheim ha inspirado, desde una perspectiva psicosocial contemporánea, y conservando sus aspectos y alcances conceptuales centrales, a la teoría de las representaciones sociales, de Serge Moscovici (1979).
} 
esencialmente social. En base a ello, Durkheim (1912) formula las principales características de las representaciones colectivas de la siguiente manera:

Las representaciones colectivas son el producto de una inmensa cooperación extendida no sólo en el tiempo, sino también en el espacio; una multitud de espíritus diferentes han asociado, mezclado, combinado sus ideas y sentimientos para elaborarlas; amplias series de generaciones han acumulado en ellas su experiencia y saber. Se concentra en ellas algo así como un capital intelectual muy particular, infinitamente más rico y complejo que el individual. (DURKHEIM, 1992, p. 14).

Por otro lado, Lucien Lévy-Bruhl, quien fue un discípulo contemporáneo de Emile Durkheim, llevó a cabo sus propios estudios acerca de las representaciones colectivas; contribuyendo, de esta manera, a profundizar y difundir el conocimiento de las mismas. Desde su propia perspectiva, y en congruencia con las ideas de Durkheim, Lévy-Bruhl (1947) en el inicio de su obra "Las funciones mentales en las sociedades inferiores" 2 , define a las representaciones colectivas de la siguiente forma:

son comunes a los miembros de un grupo social dado; se transmiten de generación en generación; se imponen a los individuos, despertando en ellos, según los casos, sentimientos de respeto, de temor, de adoración, etc., por sus objetos. No dependen del individuo para existir (LÉVY-BRUHL, 1947, p. 11).

Puede observarse entonces que también en la definición de Lévy-Bruhl -como en la de Durkheim- se sostiene, de un modo categórico, la naturaleza esencialmente social de las representaciones colectivas. En consecuencia de ello, y en relación a la dinámica social y su relación con el sistema de representaciones, en su concepción antropológica Durkheim parte de la base de que "la vida social comprende a la vez representaciones y prácticas" (DURKHEIM, 1992, p. 413). No obstante ello, se hace necesario esclarecer la suposición generalizada de que en las sociedades con una vida grupal regulada por representaciones colectivas, existía una absoluta coherencia entre su sistema de representaciones y su organización social. La inconsistencia de esta idea ha sido demostrada por el antropólogo francés Claude Lévi-Strauss, quien a partir de sus investigaciones llevadas a cabo en Brasil, afirma que "las representaciones sociológicas de los indígenas no son sólo una parte o un reflejo de su organización social; pueden

\footnotetext{
${ }^{2}$ En relación al uso del término "inferiores" para la designación de ciertos tipos particulares de sociedades tradicionales, Lévy-Bruhl aclara lo siguiente: "Mediante este término impropio, pero de empleo casi indispensable, tratamos sólo de designar a los miembros de las sociedades más simples que se conozcan". (LÉVY-BRUHL, 1947, p. 11)
} 
contradecirla completamente o ignorar ciertos elementos, como ocurre en las sociedades más avanzadas.” (LÉVI-STRAUSS, 1995, p. 162).

\section{La función de las representaciones colectivas en la determinación de la percepción y la realidad social}

Lévy-Bruhl concebía las formas de percepción de los primitivos en función de una estructuración mental basada en representaciones colectivas. De este modo, admitía que las representaciones cumplen una función de mediación entre lo "real" y el mundo social; de manera que, entonces, su imagen del mundo (imago mundi) estaba constituida por el entrelazamiento de un conjunto de mediaciones de naturaleza simbólica. Sociedades diferentes, entonces, perciben y habitan "mundos" diferentes, encontrándose esta distinción basada en el sistema representacional que es propio de cada sociedad en particular; y que responde, en última instancia, al conjunto de recursos adaptativos de la misma. Esta idea es congruente con las modernas nociones de la construcción de la realidad social, que sostienen las corrientes teóricas constructivistas (BERGER y LUCKMANN, 2003; LUHMANN, 1998). Así, las representaciones colectivas modifican las percepciones al "incluir" -en las mismas- contenidos que le son propios; produciendo, de esta manera, una verdadera construcción de realidad a través de dicha percepción. En consecuencia, a través de las representaciones colectivas, los diferentes grupos humanos definen de modos específicos su relación con la realidad, y a la realidad misma.

Esta característica de las representaciones colectivas afecta directamente la relación de los individuos con los objetos, y son por ello determinantes de sus significados (sociales), ya que por medio de las representaciones colectivas, según Lévy-Bruhl, "los objetos de cualquier especie: seres vivientes, objetos inanimados, o instrumentos salidos de la mano del hombre, no se les presentan sino cargados de propiedades místicas.” (LÉVY BRUHL, 1947, p. 67). También Durkheim acepta el carácter "constructor" de realidad de las representaciones colectivas, ya que afirma, que en el dominio social, "la idea es constructora de realidad mucho más que en cualquier otro.” (DURKHEIM, 1992, p. 214). A partir de ello, entonces, Durkheim concluye que "la sociedad se representa a sí misma y al mundo que le rodea" (DURKHEIM, 2003, p.

22). Este fenómeno constructivo, en relación a la realidad emergente y sus 
características inherentes, se debe principalmente al hecho de que, tal como sostiene Durkheim:

las representaciones colectivas atribuyen, con mucha frecuencia, a las cosas de las que se predican propiedades que en éstas no existen en forma ni grado alguno. Del objeto más vulgar pueden hacer un ser sagrado y muy poderoso. Y con todo, aunque ciertamente puramente ideales, los poderes que así le son conferidos actúan como si fueran reales; determinan la conducta de los hombres con la misma necesidad que las fuerzas físicas. (DURKHEIM, 1992, p. 213).

En este punto, y para una mejor comprensión de su mecanismo, deben tenerse en consideración las observaciones realizadas por Carl Jung sobre este hecho, quien desde un punto de vista estrictamente psicológico (y teniendo en cuenta la dimensión arquetípica humana, tal como se verá más adelante) sostiene que "toda la magia y la religión primitivas se basan sobre las influencias mágicas emanadas del objeto, que se originan en las proyecciones de contenidos inconscientes sobre el objeto." (JUNG, 1954, p. 150). Así, según Durkheim, y debido a la extensión de este fenómeno, ocurre que "las creencias religiosas no son más que un caso particular de una ley muy general. Todo el medio social nos aparece como poblado por fuerzas que, en realidad, no existen más que en nuestro espíritu." (DURKHEIM, 1992, p. 213).

Queda claro, entonces, que este fenómeno no se restringe al caso de las creencias religiosas, sino que comprende al amplio conjunto de representaciones colectivas. También, que la concepción constructivista de la "realidad" ya se encuentra presente en la teoría original de las representaciones colectivas. El fundamento de este hecho se basa, según se desprende de las ideas de Durkheim (1992), en que los datos inmediatos de la intuición sensible rara vez son recibidos e interpretados como tales, en su dimensión objetiva "natural", sino que estos datos son modificados y relacionados en base a disposiciones mentales específicas, tanto individuales como grupales. Éstas darán origen, finalmente, a las representaciones colectivas; las que, una vez constituidas y por vía reflexiva, determinan nuevamente un modo específico de decodificar la realidad del mundo exterior. Sin embargo, el hecho de que sean un resultado del espíritu humano no les quita, en la concepción de Durkheim, su propia dimensión de realidad; pudiéndose encontrar aquí también, entonces, uno de los principios de lo que la psicología moderna denomina "realidad psíquica". Por otro lado, para que esta serie de fenómenos -que 
culminan en la posibilidad de una construcción social de realidad- tenga lugar, fue necesario, en un principio, que una nueva modalidad de pensamiento emergiera durante el proceso del desarrollo de la consciencia humana: se trata del pensamiento colectivo (DURKHEIM, 1992, p. 222). Así, es el pensamiento colectivo el que, a través de su sistema de representaciones, posibilita nuevas formas de concebir la realidad; es decir, de construir una nueva realidad. $\mathrm{Y}$ es éste el nivel de realidad que determina, finalmente, las acciones y las modalidades de relación: de los individuos entre sí, y con el mundo que los rodea. De este modo, es posible encontrar en estas ideas de Durkheim los principios básicos de la realidad simbólica humana, y por ende, también del constructivismo social.

\section{Representaciones colectivas y religión}

Otra consideración importante es la relación existente entre las representaciones colectivas y la religión. Según afirma Durkheim, "los primeros sistemas de representaciones que el hombre ha elaborado sobre el mundo y sobre sí mismo son de origen religioso" (DURKHEIM, 1992, p. 8). Ello es confirmado también, en forma más específica, cuando sostiene que "las representaciones religiosas son representaciones colectivas que expresan realidades colectivas." (DURKHEIM, 1992, p. 8). Esta afirmación pone de manifiesto, así, que las representaciones colectivas y la religión comparten un nexo originario común. Por otro lado, esto le otorga a la religión, también, un importante papel en la configuración simbólica e imaginaria del mundo. Dado que las creencias religiosas son sistemas de representaciones, entonces también resulta que, desde tiempos inmemoriales, "son las creencias religiosas las que han sustituido el mundo tal como lo perciben los sentidos por un mundo diferente." (DURKHEIM, 1992, p. 221).

De este modo, las representaciones religiosas han desempeñado, a lo largo de la historia de la humanidad, un papel fundamental para la configuración del mundo, tal como lo conocemos en la actualidad. Los alcances de esta particularidad son de una importancia tal, que muchas de las actividades del hombre actual se encuentran aún vinculadas, o tienen su origen, en los diferentes sistemas religiosos. Así, por ejemplo, Durkheim asegura que: 
las realidades a las que en tal momento se refiere la especulación religiosa son las mismas que más tarde serán el objeto de la reflexión científica: se trata de la naturaleza, del hombre, de la sociedad. [...] de lo que se trata es de ligar las cosas entre sí, establecer relaciones internas entre ellas, clasificarlas, sistematizarlas. Hemos visto incluso que las nociones esenciales de la lógica tienen un origen religioso. [...] el pensamiento científico no es más que una forma más perfeccionada del pensamiento religioso. (DURKHEIM, 1992, p. 399).

Puede observarse aquí, claramente, la función de la religión como sistema clasificatorio, sistematizador de la realidad, que provee de un orden al mundo (y a través del cual lo construye); y también, la relación de continuidad que existe entre el pensamiento religioso y la ciencia. De esta manera, entonces, la religión "no es tan sólo un sistema de prácticas; es también un sistema de ideas cuyo propósito es expresar el mundo" (DURKHEIM, 1992, p. 398). Las representaciones religiosas han permitido también trazar una distinción entre dos niveles de realidad, que se conservan aún en el presente. Se trata de dos "regiones" del mundo simbólico, de dos planos fenomenológicos de la experiencia, cualitativamente diferentes, que la consciencia es capaz de transitar en distintos momentos y contextos. Corresponden al plano de lo sagrado, y al plano de lo profano. Durkheim los distingue y relaciona -a través de las creencias y representaciones religiosas- de la siguiente manera: "las creencias religiosas son representaciones que expresan la naturaleza de las cosas sagradas y las relaciones que sostienen ya sea entre sí, ya sea con las cosas profanas." (DURKHEIM, 1992, p. 36). También, y en relación a lo sagrado, esclarece y define la función de los ritos, entendiendo que éstos son reglas de conducta que establecen las prescripciones del modo en el que debe comportarse el hombre, en relación a las cosas sagradas. (DURKHEIM, 1992, p. 36).

Es importante destacar también, que las representaciones colectivas y las creencias religiosas tienen, además, una función de cohesión grupal; permitiendo, a través de las mismas, que los diferentes individuos de un grupo social determinado puedan coordinar sus acciones y prácticas, en base al hecho fundamental de poder experimentar situaciones comunes, compartidas, a partir de una decodificación e interpretación convergente de la realidad y del mundo, que tiene su fundamento en la existencia de un sistema de representaciones (colectivas) de origen común. Debido a ello, según Durkheim, la unión de los individuos de dicho grupo se debe al hecho de 
que "se representan del mismo modo el mundo sagrado y sus relaciones con el mundo profano, y porque traducen esta representación común en prácticas idénticas." (DURKHEIM, 1992, p. 39).

\section{La dimensión psicológica de las representaciones colectivas: su relación con los arquetipos y el inconsciente colectivo}

A partir de la conceptualización por parte de Durkheim de la conciencia colectiva, se hace necesario también establecer su diferenciación y relación con la consciencia individual. Surge así, en la teoría Durkheim, la concepción de la idea de "dos conciencias", que se caracteriza por establecer una clara distinción entre los aspectos individuales y los aspectos colectivos de la personalidad. Esta diferenciación es formulada, por Durkheim, del siguiente modo:

Hay en nosotros dos conciencias: una sólo contiene estados personales a cada uno de nosotros y que nos caracterizan, mientras que los estados que comprende la otra son comunes a toda la sociedad. La primera no representa sino nuestra personalidad individual y la constituye; la segunda representa el tipo colectivo y, por consiguiente, la sociedad, sin la cual no existiría. (DURKHEIM, 2004, p. 106).

Este desarrollo original de Emile Durkheim en el campo de la antropología y la sociología, vuelve a emerger algunos años más tarde en las corrientes teóricas de la psicología profunda: primero, en la teoría psicológica Carl G. Jung (JUNG, 1990), donde se establece una oposición entre el Ego (/consciencia) de naturaleza individual, y el inconsciente colectivo, de naturaleza estrictamente colectiva; y luego, en la segunda tópica de la teoría psicoanalítica de Sigmund Freud (FREUD, 1992), en el año 1923, donde esta oposición se traza entre el sistema del Yo (de naturaleza esencialmente personal) y el Superyó, un sistema caracterizado principalmente por ser el depositario de las normas, las exigencias, y los valores sociales de la época.

En el año 1916, Carl Jung (JUNG, 1990) introduce de una manera formal el concepto de inconsciente colectivo, eje fundamental de su teoría psicológica. A través de dicho concepto, Jung hace referencia a una dimensión de la estructura psíquica que trasciende la esfera de la experiencia biográfica personal del sujeto, debiendo rastrearse el origen de la misma en la historia filogenética del ser humano. Como contenido y elemento estructural del inconsciente colectivo, Jung también introduce la noción de arquetipo. En relación a ello, Jung (JUNG, 1970, p. 10) también traza una distinción y 
diferenciación entre un inconsciente personal (cuyo contenido son los complejos) y el inconsciente colectivo, que no sólo se diferencian por sus contenidos, sino también por su estructura y su historia evolutiva. En relación al inconsciente colectivo, Jung afirma que:

este inconsciente no es de naturaleza individual sino universal, es decir, que en contraste con la psique individual tiene contenidos y modos de comportamiento que son, cum grano salis, los mismos en todas partes y en todos los individuos. En otras palabras, es idéntico a sí mismo en todos los hombres y constituye así un fundamento anímico de naturaleza suprapersonal existente en todo hombre. (JUNG, 1970, p. 10).

Con respecto a los arquetipos, elementos constitutivos fundamentales del inconsciente colectivo, sostiene que los mismos son un "elemento formal, en sí vacío, que no es sino una facultas praeformandi, una posibilidad dada a priori de la forma de la representación.” (JUNG, 1970, p. 74). Aclara también, dado que ha existido sobre ello una confusión que aún se mantiene en el presente, que en relación a los arquetipos no se heredan las representaciones, sino las formas. Por lo tanto, sostiene Jung, "no se trata entonces de representaciones heredadas sino de posibilidades de representaciones." (JUNG, 1970, p. 62). De este modo, los arquetipos también funcionan como verdaderos "ordenadores de representaciones" (JUNG, 1970, p. 178), operando a nivel inconsciente. Es necesario mencionar aquí, que a nivel de la consciencia psíquica, los arquetipos sólo pueden manifestarse en calidad de imágenes, de representaciones; constituidas por contenidos y material representativo que puede provenir tanto del mundo psíquico interno, como del mundo fenoménico exterior. En este sentido, y debido a ello, los arquetipos también "señalan vías determinadas a toda la actividad de la fantasía" (JUNG, 1970, p. 62).

Pero el concepto de arquetipo no sólo comprende a la esfera psíquica individual en sentido estricto, sino que amplía su presencia a un amplio conjunto de fenómenos colectivos de naturaleza diversa, que son independientes del tiempo y del lugar. En una definición más amplia de los arquetipos, Jung afirma que "se entiende por tales las formas específicas y las series alegóricas que se encuentran de un modo análogo en todos los tiempos y regiones, como también en los sueños individuales, fantasías, visiones e ideas delirantes." (JUNG, 1954, p. 176). 
Por otro lado, los arquetipos también son definidos por Jung como "formas típicas de conducta que, cuando llegan a ser conscientes, se manifiestan como representaciones" (JUNG, 1970, p. 173). De esta manera, el concepto de arquetipo enlaza los aspectos psíquicos imaginales-representacionales con los aspectos conductuales y de acción. Tal vez, uno de los ejemplos más representativos que pueden nombrarse de esta particular correspondencia, y a nivel colectivo, sea la íntima relación vinculante que existe entre el mito, el rito, y la religión. En este sentido, debe tenerse en cuenta que Jung también denominó a los arquetipos como "temas mitológicos" (JUNG, 1954, p. 176).

En cuanto a su origen evolutivo filogenético, Jung sostiene que los arquetipos se han constituido a lo largo de innumerables generaciones, de modo que "paulatinamente se han formado en la serie ancestral por la reiteración de las experiencias." (JUNG, 1954, p. 74). En este sentido, también se hace necesario volver a mencionar y destacar las ideas de Durkheim acerca de la formación de las representaciones colectivas, según las que sostiene que "amplias series de generaciones han acumulado en ellas su experiencia y saber.” (DURKHEIM, 1992, p. 14).

\section{Arquetipos y representaciones colectivas}

Existe, desde la perspectiva de la psicología profunda junguiana, una estrecha relación entre los conceptos de inconsciente colectivo, arquetipo, mito, representación colectiva y participación mística. La mirada y el análisis de Jung sobre los aspectos psicológicos profundos, inherentes a algunas de las temáticas centrales de la antropología y la sociología, han permitido esclarecer y explicar, desde una perspectiva psicológica arquetípica, muchas de las características que Durkheim y Lévy-Bruhl le han atribuido a las representaciones colectivas y al fenómeno de la participación mística.

En primer lugar, deben esclarecerse las relaciones existentes entre las representaciones colectivas de Durkheim, y los conceptos de arquetipo y de inconsciente colectivo, de Jung. Haciendo alusión a los contenidos inconscientes colectivos, que son de tipo arcaico o primitivo, Jung afirma que "también puede aplicarse a los contenidos inconscientes la expresión "représentations collectives", que 
Lévy-Bruhl usa para designar las figuras simbólicas de la cosmovisión primitiva, pues en principio se refiere casi a lo mismo.” (JUNG, 1970, p. 11)

Queda claro entonces que, para Jung, las representaciones colectivas forman parte del inconsciente colectivo; por lo que, según su propia definición de los contenidos del inconsciente colectivo, las representaciones colectivas son, tanto desde el punto de vista estructural como del funcional, arquetipos. Sin embargo, Jung aclara que en la medida en la que las representaciones colectivas son sometidas a algún tipo de elaboración por parte de la consciencia, el término de "arquetipo" sólo puede aplicarse a ellas en forma indirecta. (JUNG, 1970, p. 11)

En realidad, esta situación no difiere de aquella en la que, con un alto grado de especificación, se designa como "imagen arquetípica" a aquella imagen o representación arquetípica que ha alcanzado el nivel de la consciencia, y como "arquetipo" a aquella estructura, de naturaleza estrictamente inconsciente, a partir de la cual dichas imágenes o representaciones arquetípicas tuvieron su origen. Así, la "representación colectiva" bien puede referirse al nivel consciente que alcanzan aquellas estructuras que, a nivel arquetípico, se encuentran presentes en los estratos colectivos profundos de la psique primitiva. No obstante esta aclaración, debe considerarse que tanto bajo la denominación de "representación colectiva", como la de "imagen arquetípica", se hace referencia a una serie de formas simbólicas representacionales que, en todos los casos, tienen sus raíces en el estrato del inconsciente colectivo de la psique.

Y es justamente debido a su relación con la estructura y la dinámica psíquica arquetípica, que -según Jung- esas représentations collectives "desde siempre han representado procesos psíquicos de transformación en forma de temas mitológicos." (JUNG, 1970, p. 47). Se obtienen aquí, entonces, dos conclusiones importantes: a) las representaciones colectivas representan procesos psíquicos de transformación, y b) dichos procesos psíquicos se representan en forma de temas mitológicos. De este modo queda establecida una clara vinculación entre las representaciones colectivas, los procesos psíquicos (que incluyen a los arquetipos del inconsciente colectivo), y los mitos. 


\section{La participación mística, según Carl Jung}

Como proceso psicológico, la participación mística fue descrita por la psicología de Carl Jung, debiendo entenderse por la misma, principalmente, una compenetración asimilativa entre la psique y el mundo circundante, fundada básicamente en mecanismos primitivos de proyección y de identificación. En función de ello, Jung sostiene que:

La condición natural del espíritu supone la existencia de esas proyecciones; es natural e innato proyectar los contenidos inconscientes. Ello crea en el individuo relativamente primitivo aquella fusión característica con el objeto, que Lévy-Bruhl acertadamente designara como "identidad mística" o "participación mística." (JUNG, 1954, p. 143).

La proyección, básicamente, consiste en un mecanismo psicológico mediante el cual los contenidos del inconsciente son depositados y percibidos en otras personas u objetos. Este proceso es un fenómeno espontáneo y natural del psiquismo inconsciente, cuya consecuencia más inmediata consiste en que la percepción de los objetos y del ambiente circundante no es "objetiva", sino que se encuentra subjetivizada debido a la percepción simultánea (como atributo de los objetos) de aquellas cualidades, contenidos, valores y características (propias del inconsciente del sujeto) que fueron depositadas en ellos, como consecuencia de la proyección. Así, en la participación mística, el sujeto no es capaz de llevar a cabo una clara diferenciación entre sí mismo y el objeto; por ello, "lo que sucede fuera sucede también en su interior, y lo que ocurre en su interior ocurre también fuera." (JUNG, 2004, p. 155). Es importante destacar aquí, que el sujeto no es consciente de dicho proceso; la proyección es un mecanismo inconsciente. Debido a la proyección, los individuos trazan relaciones imaginarias con el mundo, que desde un punto de vista objetivo, no forman parte de aquél.

De esta manera, y a través de la participación mística, se hace posible dar cuenta de uno de los mecanismos psicológicos más primitivos y fundamentales del ser humano, que permite llevar a cabo, también, el trazado de la primitiva relación originaria entre el psiquismo y la religión.

\section{Psicología y religión: una perspectiva arquetípica}

Desde la perspectiva de la psicología analítica de Carl Jung, la dimensión arquetípica y mitológica del psiquismo se encuentra estrechamente vinculada a la 
fenomenología de la religión. Desde este enfoque, la religión es un fenómeno perteneciente al campo psíquico, y por ello su importancia trasciende ampliamente aquellos significados que la vinculan exclusivamente con las cuestiones de fe, de práctica, o de creencia; ya que sus raíces estructurales profundizan hasta los orígenes mismos de la humanidad y los inicios del desarrollo de la sociedad. Por esto, Jung formula que "dentro de la realidad psicológica, las ideas religiosas no descansan meramente sobre la tradición y la fe sino que derivan de los arquetipos" (JUNG, 1970, p. 166); señalando además que, justamente debido a su carácter estructural y funcional arquetípico, estos aspectos religiosos conservan un alto grado de autonomía en su funcionamiento, debido a que "los arquetipos siempre existen y actúan; no tienen en sí necesidad de fe alguna" (JUNG, 1970, p. 166).

Por otro lado, para Jung, dado que las representaciones religiosas se encuentran relacionadas directamente con los arquetipos, ocurre que "se puede también contar con la existencia en todos los hombres de los factores religiosos normales, o sea de los arquetipos" (JUNG, 1970, p. 58). De este modo, se pone en evidencia que la dimensión religiosa corresponde a un nivel funcional y estructural normal del ser humano; es decir, presente en todos los hombres. No debe olvidarse que para Durkheim, tal como se había mencionado ya, los primeros sistemas de representaciones colectivas son sistemas de representaciones religiosas. Así, se pone en evidencia también, una vez más, la relación entre las representaciones colectivas, la religión, y los arquetipos. Por lo tanto, puede afirmarse que la dimensión religiosa es, fundamentalmente, una dimensión arquetípica. Y por ello, también resulta indisociable de la realidad psíquica humana, a punto tal de que a través de su vasta y compleja matriz de imágenes y símbolos, "la religión constituye, ciertamente, una de las más tempranas y universales exteriorizaciones del alma humana" (JUNG, 1949, p. 7).

Es por esto que también, según afirma Jung (1949), "la religión presenta un aspecto psicológico muy significativo" (JUNG, 1949, p. 7); a punto tal que -sostieneexisten hechos que ponen en evidencia "la existencia de una auténtica función religiosa en lo inconsciente" (JUNG, 1949, p. 7). De este modo, también, es posible hablar de un verdadero "simbolismo religioso de los procesos inconscientes" (JUNG, 1949, p. 7). En función de estas circunstancias, en relación a las vinculaciones existentes entre la 
dimensión religiosa y la psique, es posible concluir -tal como afirma Jung- que "la religión es una actitud especial del espíritu humano" (JUNG, 1949, p. 8).

Esta particular relación entre psique y religión exige también, así, a las ciencias psicológicas redefinir en muchos casos su perspectiva y conceptualización acerca de la importancia que la dimensión religiosa representa para el dinamismo, la funcionalidad, el desarrollo y la evolución del psiquismo humano. Y esto implica además, necesariamente, una reformulación del lugar y la importancia -en tanto objeto de estudio- de la fenomenología religiosa dentro del marco conceptual y epistemológico de dichas ciencias. Es por ello que Jung (1949) sostiene que:

todo tipo de psicología que se ocupe de la estructura psicológica de la personalidad humana, habrá por lo menos de tener en cuenta que la religión no sólo es un fenómeno sociológico o histórico, sino, también, un importante asunto personal para crecido número de individuos. (JUNG, 1949, p. 7).

Otro punto importante a considerar, en relación a las vinculaciones arquetípicas entre psique y religión, es lo concerniente a la fenomenología del espíritu. El "espíritu", sostiene Jung (1970), también corresponde a un fenómeno psíquico ligado a la dinámica de los arquetipos, ya que, bajo ciertas condiciones, "la aparición de los arquetipos tiene un declarado carácter numinoso que, si no se quiere llamar "mágico", hay que llamar espiritual." (JUNG, 1970, p. 149).

Y conjuntamente con los arquetipos -y ligada a ellos-, y determinando además una de las principales funciones psíquicas y sociales de la religión, también es posible encontrar, como parte constitutiva del plano psicológico humano, una extensa matriz de imágenes y símbolos religiosos. Los mismos, sostiene Jung (1954), "permiten al hombre erigir una posición espiritual antagónica a la primitiva naturaleza instintiva, una actitud cultural frente a la mera instintividad. Tal fue siempre la función de todas las religiones" JUNG, 1954, p. 82). Así, el espíritu aparece posicionado como una polaridad complementaria del instinto; resultando, además, en estrecha cercanía al plano de la función religiosa y del dinamismo psíquico en general.

Por último, en torno a lo arquetípico, lo religioso, y lo espiritual, aparece también, necesariamente, el problema vinculado a la dimensión ontológica de la idea de Dios. La posición de Jung (1954) al respecto resulta absolutamente clarificadora, afirmando además que dicha problemática necesariamente debe ser un objeto de estudio 
contemplado por la psicología. Jung basa su argumentación en función de que "en física podemos pasar sin un concepto de Dios, pero en psicología, la noción de la divinidad es un factor definitivo con el que hay que contar, tanto como con las nociones de "afecto", "instinto", "madre", etc.” (JUNG, 1954, p. 160). En muchos pasajes de su obra, Jung insiste en que no se trata de discutir o demostrar la existencia o no existencia de "Dios", pues esto representa, en última instancia, un problema de otra índole. De lo que se trata, en cambio, es de reconocer la realidad (y sus alcances fenomenológicos) de la presencia de la idea o imagen de "Dios" en la psique humana. Este hecho innegable, de naturaleza arquetípica, se ha reiterado una y otra vez, en todo tiempo, y en todo lugar. Así, según Jung (1954), “en la eterna confusión entre objeto e imago estriba el no poder diferenciar entre "Dios" e imago de "Dios"' (JUNG, 1954, p. 160). Por lo tanto, de lo que se ocupa la psicología arquetípica es de la presencia de la imagen de Dios en la psique, al igual que de sus efectos, sus manifestaciones, sus relaciones, sus funciones, y de todos aquellos fenómenos que, en forma directa o indirecta, se encuentran de alguna manera relacionados a dicha imagen. El problema se restringe, así, al efecto psíquico de una imago; no involucrando entonces, como parte del mismo, a una posible entidad en sí misma.

\section{Mito, psique y sociedad}

La exploración de las interrelaciones entre arquetipos, psique y religión requiere, como consideración adjunta necesaria, la inclusión de dos niveles simbólicos de representación adicionales: el del mito y el de la sociedad.

A lo largo de la historia, las visiones que el hombre ha tenido acerca del mundo y la realidad han atravesado cambios sustanciales. Cada cosmovisión particular siempre ha necesitado de un referente conceptual que la legitime, y posibilite su continuidad. Mitos y religiones; creencias, dogmas y leyes; sistemas filosóficos y políticos; ideologías y teorías científicas; son parte del complejo entramado simbólico que opera a modo de soporte estructurador y organizador de las distintas formas que adquieren, en un momento histórico y lugar determinado, las sociedades humanas.

Desde las nociones de conciencia colectiva y de representaciones colectivas, de Emile Durkheim (2004 / 2003), la idea de una realidad social / mundo como resultado de una construcción, a partir de la intervención de estructuras y sistemas 
simbólicos referenciales colectivos, posee en la actualidad una amplia fundamentación teórica.

\section{Los universos simbólicos}

En las así llamadas sociedades "primitivas", gran parte de su organización social se encuentra fundamentada en base a la mitología y la religión; o, más específicamente, en base al conjunto de representaciones que estructuran a sus "universos simbólicos". El concepto de universo simbólico es utilizado, dentro del campo de la sociología, por Peter Berger y Thomas Luckmann (2003) para hacer referencia al modo particular que tienen las sociedades de organizar su estructura interna, permitiendo la integración, funcionalidad y cohesión social a través de las diferentes formas de legitimación. Según estos autores, los universos simbólicos son "cuerpos de tradición teórica, que integran zonas de significado diferentes y abarcan el orden institucional en una totalidad simbólica" (BERGER y LUCKMANN, 2003, p. 122).

La constitución de estos universos, como etapa fundamental de la organización social, da origen a un escenario con características específicas, dentro del cual la vida social se desenvuelve de acuerdo a ciertas pautas que quedan preestablecidas desde el momento mismo de su creación. Se establece un límite que marca un "adentro" y un "afuera" de la sociedad, generando un sistema de interacciones regido por principios que le son propios y que la identifican. Así, Berger y Luckmann sostienen que:

todos los sectores del orden institucional se integran, sin embargo, en un marco de referencia general, que ahora constituye un universo en el sentido literal de la palabra, porque ya es posible concebir que toda la experiencia humana se desarrolla dentro de aquél. (BERGER y LUCKMANN, 2003, p. 123)

Esta estructuración de los universos simbólicos representa uno de los principales pasos en la construcción social de realidad, ya que a partir del momento mismo de su instauración queda excluida, para los actores sociales que pertenecen a una

\footnotetext{
3 También Lévi-Strauss, en relación al uso controvertido de este término, aclara: "No obstante todas sus imperfecciones y pese a merecidas críticas, parece evidente que el término «primitivo», a falta de otro mejor, ha pasado a ocupar un lugar definitivo en el vocabulario etnológico y sociológico contemporáneo." (LÉVI-STRAUSS, 1995, p. 137)
} 
determinada comunidad, cualquier otra alternativa referencial que sea externa a los límites de dicho universo. El universo constituido se "cierra" sobre sí mismo, y toda posibilidad de significación se restringe al espacio de los significados que le son propios. Así, de acuerdo a Berger y Luckmann, “el universo simbólico se concibe como la matriz de todos los significados objetivados socialmente y subjetivamente reales; toda la sociedad histórica y la biografía de un individuo se ven como hechos que ocurren dentro de ese universo." (BERGER y LUCKMANN, 2003, p. 123). De esta manera, la "matriz de todos los significados objetivados socialmente" se presenta, a los ojos de un observador, bajo la forma de un "mundo".

\section{El mito como matriz de realidad social}

A fines del siglo XIX, y a lo largo del siglo XX, el estudio de los mitos y las religiones había cobrado un particular interés desde distintas disciplinas, entre las que se destacaron principalmente la antropología, la sociología y la psicología. Con abordajes y teorías muchas veces dispares y antagónicas, cada una de estas ramas del conocimiento ha creído poder esclarecer los aspectos fundamentales de esta particular construcción humana. Más allá de las respectivas definiciones y las diferencias interpretativas que las distancian, estas corrientes han reconocido, sin embargo, la importancia que el mito ha tenido -y tiene- en el desarrollo histórico de la sociedad; o, más específicamente, en términos de la sociología moderna, el lugar y la función del mito en la construcción de realidad social.

Mircea Eliade (1992) hace referencia a la función del mito en las "sociedades tradicionales" o "primitivas", "sociedades en las que el mito tiene -o ha tenido hasta estos últimos tiempos- "vida", en el sentido de proporcionar modelos a la conducta humana y conferir por eso mismo significación y valor a la existencia." (ELIADE, 1992, p. 10). Según Eliade, "la función principal del mito es revelar los modelos ejemplares de todos los ritos y actividades humanas significativas: tanto la alimentación o el matrimonio como el trabajo, la educación, el arte o la sabiduría." (ELIADE, 1992, p. 14).

Puede observarse, en las definiciones que Eliade da de las sociedades tradicionales, el papel y la función que los mitos desempeñan en ellas, en cuanto referentes para la fundamentación y justificación de las conductas y actividades que tienen lugar en dicho contexto social. El mito, como "realidad cultural extremadamente 
compleja" (ELIADE, 1992, p. 12), ejerce a nivel social, psicológico y cognoscitivo una influencia decisiva para los integrantes de una comunidad, ya que, según Eliade, "el mito se considera como una historia sagrada y, por tanto, una "historia verdadera", puesto que se refiere siempre a realidades." (ELIADE, 1992, p. 13). Y esto también tiene su efecto, en forma directa, sobre el valor de los objetos y las acciones. Según afirma Mircea Eliade (1993), en su libro "El mito del eterno retorno":

los objetos del mundo exterior, tanto, por lo demás, como los actos humanos propiamente dichos, no tienen valor intrínseco autónomo. Un objeto o una acción adquieren un valor $\mathrm{y}$, de esta forma, llegan a ser reales, porque participan, de una manera u otra, en una realidad que los trasciende. (ELIADE, 1993, p. 14).

Y, en este sentido, el mito representa -y constituye- dicha realidad trascendente. De este modo, la realidad mítica y la experiencia mundana se fusionan bajo la forma de una integración congruente, que se manifiesta como una "realidad" que abarca la totalidad de la existencia, y más allá de la cual se agotan todas las demás posibilidades fenomenológicas de conocimiento, vivencia y acción. El mito se convierte, así, en la instancia simbólica mediadora que condiciona las formas del mundo y su interpretación.

Por sus características, el entramado resultante de la realidad mítica constituye un universo simbólico. Según Berger y Luckmann (2003), "se puede afirmar con certeza que la mitología representa la forma más arcaica para el mantenimiento de universos, así como en verdad representa la forma más arcaica de legitimación en general." (BERGER y LUCKMANN, 2003, p. 139). En consecuencia, siguiendo su línea de pensamiento, añaden también en relación a ello que "esta concepción entraña naturalmente un alto grado de continuidad entre el orden social y el cósmico, y entre todas sus respectivas legitimaciones: toda la realidad aparece como hecha de una misma materia.” (BERGER y LUCKMANN, 2003, p. 140). Así, las vinculaciones entre mito y legitimación dan cuenta de la importancia que esta "realidad" tiene para el establecimiento del orden social; como así también del modo en el que las mismas se articulan, en otro nivel, con los aspectos políticos e ideológicos de la sociedad.

En relación a esto, y desde una perspectiva estructuralista, también Claude LéviStrauss (1995) entiende que "los órdenes «concebidos» corresponden al campo del mito y la religión. Se puede preguntar si la ideología política de las sociedades 
contemporáneas no pertenece también a esta categoría." (LÉVI-STRAUSS, 1995, p. 334). Esta formulación de Lévi-Strauss se basa en que, según este autor, existen en la sociedad un conjunto de estructuras que corresponden a diferentes tipos de "órdenes" (LÉVI-STRAUSS, 1995, p. 334). Así, traza una distinción entre los órdenes vividos y los órdenes concebidos. Los órdenes vividos son independientes de la representación que los hombres tienen de la realidad, es decir, "son a su vez función de una realidad objetiva" (LÉVI-STRAUSS, 1995, p. 334). En cambio, las "estructuras de orden «concebidas», [...] no corresponden directamente a ninguna realidad objetiva." (LÉVISTRAUSS, 1995, p. 334).

En función de lo visto, se hace necesario entonces despojar al mito de toda "ingenuidad" o carácter "infantil" (en términos de historia humana), con el que muchas veces se ha pretendido interpretarlo desde distintas disciplinas. Tampoco cabe imaginar el desarrollo del pensamiento mitológico como el mero resultado del azar y la irracional espontaneidad humana, ya que, según afirman Berger y Luckmann (2003), los "sistemas mitológicos más elaborados se esfuerzan por eliminar incoherencias y mantener el universo mitológico en términos integrados teóricamente." (BERGER y LUCKMANN, 2003, p. 141).

Si el mito, como se ha visto, posibilita dar forma y construir aspectos relevantes de la realidad social (como por ejemplo objetos y acciones), la cuestión que cabe abordar ahora es cómo el mito adquiere su propia forma, cómo se estructura y sostiene a lo largo del tiempo, y a través de qué mecanismos contribuye a la construcción de la realidad / mundo de la que él mismo forma parte. También, si se considera que ese nivel de realidad se corresponde con el espacio mítico, con todas sus imágenes y símbolos, se hace necesario indagar cuál es el soporte y el vehículo de esta realidad, permitiendo que la misma adquiera el carácter de experiencia común / colectiva, para los miembros de una sociedad. Y es aquí, entonces, donde nuevamente debe considerarse la función y la importancia de la dimensión psicológica arquetípica de los mitos.

\section{Mitos, arquetipos, e inconsciente colectivo}

Si bien a lo largo de la historia el mito se ha ido plasmando a través de objetivaciones sociales como los ritos, la religión, la arquitectura, las instituciones, el arte, la literatura, la música, etc., el mito está asociado, desde sus orígenes y en el plano 
psicológico, a las representaciones colectivas; es decir, también -tal como se ha visto-, a los arquetipos y al inconsciente colectivo. Esto produce, naturalmente, un punto de enlace entre los diferentes planos sociales vinculados al mito, y el plano psíquico arquetípico. Es por ello que Jung sostiene que "el contenido esencial de todas las mitologías, de todas las religiones [...] es de naturaleza arquetípica" (JUNG, 1970, p. $150)$.

También, debe destacarse que así como los arquetipos se manifiestan a nivel psíquico en cada persona de un modo individual (por ejemplo, en los sueños), existe otro nivel, de orden social-colectivo, en el que "los arquetipos aparecen como mitos en la historia de los pueblos" (JUNG, 1970, p. 63). Y esto se debe fundamentalmente a que "los mitos son ante todo manifestaciones psíquicas que reflejan la naturaleza del alma." (JUNG, 1970, p. 12). Esta correlación y paralelismo entre el plano psíquico y el plano social-colectivo es de una naturaleza tal, que Jung en ocasiones también denomina a los arquetipos como "temas mitológicos" (JUNG, 1970, p. 54). Y es por ello que también afirma que "el alma contiene todas las imágenes de que han surgido los mitos" (JUNG, 1970, p. 13), dando lugar, así, a una conceptualización del mito como una "representación de hechos psicológicos" (JUNG, 1954, p. 54). De esta forma y a modo de conclusión, puede afirmarse que, tal como sostiene Jung (1954):

en la medida en que el mito no es sino una proyección de lo inconsciente, y de ningún modo una invención consciente, no sólo se explica que siempre nos encontremos con los mismos temas mitológicos, sino también que el mito represente típicos fenómenos psíquicos. (JUNG, 1954, p. 54).

\section{Consideraciones finales}

Tal como se ha puesto en evidencia a través del análisis realizado, a lo largo de la historia el origen y el desarrollo de las religiones, los mitos, las sociedades y la psique, han compartido -y aún comparten- niveles simbólicos que les son comunes.

La existencia de un sustrato de naturaleza arquetípica, que configura y determina los procesos de la estructuración y del dinamismo psíquico y social, aparece como una dimensión simbólica integradora, que comprende el extenso horizonte de la experiencia fenomenológica humana. 
La teoría psicológica de Carl Jung ofrece, a través de su perspectiva arquetípica, un conjunto de recursos conceptuales que permiten y facilitan el análisis y la comprensión de dicha dimensión simbólica, posibilitando también hacer visibles -y facilitando su interpretación- las complejas interrelaciones existentes entre la religión, el mito, la psique y la sociedad.

De este modo, a través de las nociones fundamentales de arquetipo e inconsciente colectivo, las formas, estructuras y funciones psico-sociales de la religión, el mito, la psique y la sociedad, ya no aparecen como manifestaciones autónomas e independientes, sino como los elementos emergentes de un único y mismo proceso psico-socio-evolutivo que, a lo largo del tiempo y como partes necesarias interdependientes, los integra.

\section{Referencias}

BERGER, P. y LUCKMANN, T. La construcción social de la realidad. Buenos Aires: Amorrortu, 2003.

DURKHEIM, E. Sociología y filosofía. Buenos Aires: Editorial Guillermo Kraft Limitada, 1951.

DURKHEIM, E. Las formas elementales de la vida religiosa. Madrid: Ediciones Akal, 1992.

DURKHEIM, E. Las reglas del método sociológico. Buenos Aires: Ediciones Libertador, 2003.

DURKHEIM, E. La división del trabajo social. Buenos Aires: Ediciones Libertador, 2004.

ELIADE, M. Mito y realidad. $2^{\text {a }}$ Ed. Barcelona: Editorial Labor, 1992.

ELIADE, M. El mito del eterno retorno. Barcelona: Alianza Editorial, 1993.

FREUD, S. El yo y el ello. En: Obras completas. Volumen XIX. El yo y el ello, y otras obras (1923-1925). Buenos Aires: Amorrortu Editores, 1992.

JUNG, C. G. Psicología y Religión. Buenos Aires: Editorial Paidós, 1949.

JUNG, C. G. Energética psíquica y esencia del sueño. Buenos Aires: Editorial Paidós, 1954.

JUNG, C. G. Arquetipos e inconsciente colectivo. Barcelona: Editorial Paidós, 1970. 
JUNG, C. G. Two Essays on Analytical Psychology. 2nd ed. Collected Works. Vol.7 . London: Routledge, 1990.

JUNG, C.G. La dinámica de lo inconsciente. Obra Completa. Vol. 8. Madrid: Editorial Trotta, 2004.

LÉVI-STRAUSS, C. Antropología estructural. Barcelona: Ediciones Paidós, 1995.

LÉVY BRUHL, L. Las funciones mentales en las sociedades inferiores. Buenos Aires: Editorial Lautaro, 1947.

LUHMANN, N. Sistemas Sociales. Lineamientos para una Teoría General. $2^{\text {a }}$ Ed. Barcelona: Anthropos, 1998.

MOSCOVICI, S. El psicoanálisis, su imagen y su público. Buenos Aires: Editorial Huemul S.A., 1979.

Recebido: 22/06/2015

Received: 06/22/2015

Aprovado: 07/07/2015

Approved: 07/07/2015 